\title{
Neonatal survival and kidney function after prenatal interventions for obstructive uropathies
}

\author{
Marcin Tkaczyk ${ }^{1}$, Malgorzata Stanczyk ${ }^{1}$, Waldemar Krzeszowski ${ }^{2}$, Justyna Wojtera ${ }^{2}$, \\ Magdalena Litwinska², Katarzyna Fortecka-Piestrzeniewicz ${ }^{3}$, Tomasz Talar ${ }^{4}$, \\ Barbara Pawlowska ${ }^{4}$, Dariusz Olejniczak ${ }^{5}$, Michal Podgorski ${ }^{6}$, Rafal Swiechowski ${ }^{7}$, \\ Adrian Krygier ${ }^{7}$, Agnieszka Wosiak ${ }^{8}$, Krzysztof Szaflik ${ }^{2}$ \\ ${ }^{1}$ Department of Paediatics, Immunology and Nephrology, Polish Mother's Memorial Hospital Research Institute of Lodz, \\ Lodz, Poland \\ ${ }^{2}$ Department of Gynecology, Fertility and Fetal Therapy, Polish Mother's Memorial Hospital Research Institute, Lodz, Poland \\ ${ }^{3}$ Department of Intensive Therapy and Congenital Malformations of Newborns and Infants, \\ Polish Mother's Memorial Hospital Research Institute, Lodz, Poland \\ ${ }^{4}$ Department of Neonatology, Polish Mother's Memorial Hospital Research Institute, Lodz, Poland \\ ${ }^{5}$ Department of Surgery, Urology and Transplantology, Polish Mother's Memorial Hospital Research Institute, Lodz, Poland \\ ${ }^{6}$ Department of Imaging Diagnostic, Polish Mother's Memorial Hospital Research Institute, Lodz, Poland \\ ${ }^{7}$ Medical Laboratory Diagnostic Centre, Polish Mother's Memorial Hospital Research Institute, Lodz, Poland \\ ${ }^{8}$ Institute of Information Technology, Lodz University of Technology, Lodz, Poland
}

\begin{abstract}
Objectives: Prenatal interventions in LUTO (lower urinary tract obstruction) usually are still question of a debate between gynaecologist and paediatric nephrologist. We aimed the study to assess the early survival rate and renal outcome in LUTO foetuses.

Material and methods: The study was a prospective data analysis of 39 foetuses from singleton pregnancies. All pregnant women with LUTO in the foetus were qualified for VAS based on a local practice. The mean time of first urine analysis ranged between 13-30 weeks of pregnancy. Primary end-point analysis included live birth, 28d-survival, pulmonary and renal function assessment in neonatal period.

Results: From initial number of 39, six patients miscarried before the procedure was performed. Overall, 33 VAS were performed at the mean 21 week of pregnancy (range 14-30 weeks). 25/39 foetuses survived until delivery. Three neonates died in first 3 days of life. In the first month 3 children required peritoneal dialysis, but at 28 day all children were dialysis-free. Overall survival rate at 28 day was $56 \%$. Renal function preservation of the initial group (39) turned out to be low - 18\% (7/39).

Conclusions: Our study showed average survival curves and complications. LUTO in the foetus had mostly unfavourable outcome in the neonatal period. The prenatal intervention did not increase it significantly and did not guarantee the preservation of normal kidney function.
\end{abstract}

Key words: obstructive uropathy; posterior urethral valves; vesico-amniotic shunting; kidney function; prenatal; neonate

Ginekologia Polska 2019; 90, 7: 416-422

\section{INTRODUCTION}

Proper diagnosis and prenatal treatment of foetal lower urinary tract obstruction (LUTO) still constitutes a great challenge for obstetricians and neonatologists despite the significant progress in last 30 years [1, 2]. Clinically significant LUTO is detected in 1:10-20000 pregnancies [3]. Male foetuses with posterior urethral valves (PUV) prevail, but female foetuses may also develop LUTO due to urethral stenosis or atresia $[3,4]$.

According to the latest studies success rates measured by 2 -y survival ranges from $21-72 \%$, depending on the study intervention [5, 6]. It might be assumed that the long-term renal function depends mostly on the number of nephrons, dysplastic and cystic changes that had occurred before urine 
production start. This may be related to multiple genetic, epigenetic and environmental factors of early pregnancy, before any intervention is possible [7].

Prenatal interventions in LUTO usually comprise vesico-amniotic shunting (VAS) or laser valve ablation, which in selected cases are accompanied by amnioinfusions. These procedures may prevent pulmonary hypoplasia and progression of irreversible renal damage [3]. There was at least one attempt to prove the effectiveness of VAS in randomised controlled trial, but it did not show enough strength to draw firm conclusions [8]. However, some observational data and metaanalyses suggested that VAS may improve perinatal survival, but without significant influence of renal survival [9].

Because of the lack of randomised control trials and controversies about the interventions, there is still a place for observational trials in this field. Thus, the aim of our study was to assess the neonatal outcome in an unselected cohort of prenatally detected LUTO qualified for VAS.

\section{MATERIAL AND METHODS}

The study was a prospective observational trial (y.:20162018) led in the tertiary multidisciplinary reference centre on neonatal outcome in the cohort of foetuses diagnosed prenatally with LUTO and qualified for prenatal intervention. The study team comprised of 10 physicians (obstetricians, neonatologists, urologists and nephrologists), who were trained in the protocol.

The study was accepted by the Local Ethics Committee of Polish Mother's Memorial Hospital Research Institute (No:1/2016) and conducted according to the Declaration of Helsinki. All the pregnant women, and later parents and guardians of the neonates gave informed consents for participation in the study.

Inclusion criteria of the study were:

1. obstructive uropathy by ultrasound with megabladder detected in at least 2 separate examinations with or without hydronephrosis, with normal or reduced amniotic fluid volume
2. singleton pregnancy

3. patient consent for prenatal intervention

Foetuses with multiple genetic abnormalities and/or abnormal karyotype were excluded from further evaluation.

\section{Study group characteristics}

All the patients diagnosed with LUTO between January 2016 and December 2017 in whom the LUTO was detected by repeated ultrasound were offered a prenatal intervention of VAS and a prenatal and postnatal follow-up in the reference centre. The decision of prenatal intervention was based on clinical experience of an experienced obstetric team and the parents (local criteria for intervention: enlarged bladder, reduced amniotic fluid, hydronephrosis - uni or bilateral). The urinary analysis was done but did not constitute a contraindication for the intervention. Parenchymal kidney changes were noted but did not influence the qualification. Finally, 39 patients entered the study. Clinical characteristics of patients is presented in Table 1.

Preoperatively, a detailed ultrasound examination (Voluson E8, GE Healthcare) was carried out to confirm the diagnosis of obstructive uropathy and exclude any other major defects. Obstructive uropathy was diagnosed by the presence of enlarged bladder (megabladder) with or without "keyhole"sign. A diagnostic"keyhole"sign is seen in PUV, indicating continuity between distended bladder and the dilated posterior urethra proximal to the valves. Changes in renal parenchyma - increased echogenicity or structure and cyst formation were also described (Tab. 2). Oligohydramnios was defined by single deepest pocket of less than $2 \mathrm{~cm}$.

\section{Vesico-amniotic shunting procedure}

Ultrasound scanning was used to obtain a transverse section of the enlarged bladder and define the appropriate site of entry on the maternal abdomen which was infiltrated with local anesthetic ( $10 \mathrm{~mL}$ of $1 \%$ lignocaine) down to the myometrium. Under continuous ultrasound guidance, the

Table 1. Prenatal characteristics of the study group. Continuous data presented as median value and min-max range)

\begin{tabular}{|l|l|l|l|l|}
\hline & $\begin{array}{l}\text { All foetuses } \\
\mathbf{N}=\mathbf{3 9}\end{array}$ & $\begin{array}{l}\text { Survivors at 28d. } \\
\mathbf{n = 2 2}\end{array}$ & $\begin{array}{l}\text { Non-Surivors } \\
\mathbf{n = 1 7}\end{array}$ & Statistical difference \\
\hline Mother age [y] & $29(18-38)$ & $29(18-38)$ & $29(19-37)$ & $>0.05$ \\
\hline Pregnancy & $1.5(1-5)$ & $2(1-5)$ & $1.5(1-3)$ & $>0.05$ \\
\hline Week of diagnosis of LUTO & $18(12-30)$ & $18(13-30)$ & $17(12-21)$ & $>0.05$ \\
\hline AFI [cm] & $6(0-21)$ & $8(0-21)$ & $3(0-21)$ & 0.04 \\
\hline Week of intervention - shunting & $21(14-30)$ & $22(14-30)$ & $20(16-23)$ & 0.06 \\
\hline Number of shunts/patient & $1.5(1-5)$ & $2(1-5)$ & $1.5(1-3)^{*}$ & $>0.05$ \\
\hline Need for amnioinfusions & $18 / 39$ & $12 / 22$ & $6 / 17$ & NA \\
\hline
\end{tabular}

* only 11 were shunted; AFI — amniotic fluid index; LUTO — lower urinary tract obstruction 


\begin{tabular}{|c|c|c|c|c|c|c|}
\hline $\begin{array}{l}\text { Megabladder } \\
\text { only }\end{array}$ & $\begin{array}{l}\text { Megabladder and } \\
\text { hydronephrosis }\end{array}$ & $\begin{array}{l}\text { Only bilateral } \\
\text { hydronephrosis }\end{array}$ & $\begin{array}{l}\text { Renal parenchymal } \\
\text { changes - } \\
\text { echogenicity }\end{array}$ & $\begin{array}{l}\text { Renal cysts } \\
\text { present }\end{array}$ & $\begin{array}{l}\text { Renal cysts or changes } \\
\text { in echogenicity }\end{array}$ & Oligohydramnios \\
\hline $\begin{array}{l}19 / 39 \\
51 \%\end{array}$ & $\begin{array}{l}14 / 39 \\
36 \%\end{array}$ & $\begin{array}{l}5 / 39 \\
13 \%\end{array}$ & $\begin{array}{l}22 / 39 \\
56 \%\end{array}$ & $\begin{array}{l}25 / 39 \\
64 \%\end{array}$ & $\begin{array}{l}29 / 39 \\
74 \%\end{array}$ & $\begin{array}{l}30 / 39 \\
85 \%\end{array}$ \\
\hline
\end{tabular}

\begin{tabular}{|c|c|c|c|c|}
\hline & All subjects & Survivors at $\mathbf{2 8 d}$ & Non-survivors & Statistical difference \\
\hline sodium $[\mathrm{mmol} / \mathrm{L}]$ & $104(50-146)$ & $91(50-146)$ & $116(50-127)$ & 0.17 \\
\hline chloride $[\mathrm{mmol} / \mathrm{L}]$ & $84(5-145)$ & $80(5-146)$ & $95(66-114)$ & 0.17 \\
\hline B2-microglobuline & $7.1(0.4-24.7)$ & $6.7(0.4-17.0)$ & $10.7(2.2-24.7)$ & 0.14 \\
\hline Osmolarity $\left[\mathrm{mOsm} / \mathrm{kg} \mathrm{H}_{2} \mathrm{O}\right]$ & $223(96-289)$ & $187(96-289)$ & $241(164-264)$ & 0.08 \\
\hline
\end{tabular}

shunt (diameter $2 \mathrm{~mm}$, length $12 \mathrm{~cm}$; Rocket KCH Fetal Bladder Catheter, Washington, United Kingdom) was inserted.

In the foetal urine selected markers of prognosis were assessed: sodium (normal $<100 \mathrm{mmol} / \mathrm{l}$ ), chloride (nor$\mathrm{mal}<90 \mathrm{mmol} / \mathrm{L}$ ), $\beta 2$ microglobulin (SO-314.501 LIAISON beta 2- microglobulin; normal $<4.0 \mathrm{mg} / \mathrm{L}$ ) concentration and urine osmolarity (normal $<200 \mathrm{mOsm} / \mathrm{kg} / \mathrm{H}_{2} \mathrm{O}$ ). The values of these predictive indices in the study group are given in Table 3. They were analysed according to the criteria cited in the last review by Smith-Harrison [3]. Pregnancy duration and delivery procedures were analysed according to the outcome (demise, termination, still birth, live birth).

\section{Neonatal assessment}

After delivery the neonate was assessed with basic anthropometry and Apgar score. On the $4^{\text {th }}$ day clinical and biochemical variables were analysed: survival renal function (eGFR and absolute creatinine [10]), albuminuria (albumin/creatinine ratio: $\mathrm{ACR}$ ) and urine output, pulmonary function (ventilation dependency, clinical and radiological signs of pulmonary hypoplasia) and central nervous system (CNS) injury. Within first 28 days LUTO was confirmed/excluded by micturating cystogram/cystoscopy. Urologic interventions also were assessed. Clinical data were gathered with regard to the urine output, ventilation support and vasopressors need. Blood pressure was measured with oscillometric devices to exclude hypertension.

Urinary tract was assessed by a radiologist experienced in paediatric ultrasound. The Samsung RS80 device with convex/microconvex and linear probes were used.

Kidney injury was measured by serum creatinine (ELISA) compared with reference values of Rudd et al. [10] eGFR calculation was performed according to the Schwartz formula (with $k$ value of 0.33 for neonates) and presence of albuminuria (albumin/creatinine ratio - ACR) [11]. Albumin excretion was compared to the data obtained in preterm babies from the study of Gubhaju et al [12]. Children were tested for presence of acidosis. The study had 2 primary endpoints: survival and kidney injury symptoms at $28^{\text {th }}$ day of life.

\section{Statistical methods}

Data analysis was performed using Statistica package version 12 (StatSoft Inc., USA) with medical add-in. All parameters were tested for normal distribution using Shapiro-Wilk W test and were presented as means with standard deviation. Comparisons of differences in characteristics between two groups (survivors and non-survivors) were performed using the Student's t-test and Mann-Whitney $U$ test depending on the distribution of data. The differences between proportions were evaluated by chi-squared test.

The assessment of the validity of prenatal markers for 28day survival was performed with discriminative analysis and a probabilistic predictive Naïve Bayes model. A Wilks lambda test was used to test for significant differences between the groups on the individual predictor variables. A significance level of $p<0.05$ was considered significant. A receiver operating characteristic (ROC) curve with sensitivity and precision were applied to examine the correctness of the predictive model. The Kaplan-Meyer estimator was used for estimation the survival function.

\section{RESULTS}

Amongst the study group all pregnant women accepted the prenatal intervention. However, six patients miscarried before the procedure was performed. Overall, 33 VAS were performed at the mean 21 week of pregnancy (range 1430 weeks). No pregnancy lost was noted as a complication of prenatal interventions. In 6 cases there was a dislodgement/blockage of the shunt and procedure was repeated. Mean number of interventions was 1.5/foetus (range 1-5) — detailed data are presented in Figure 1. In 18 cases prior 


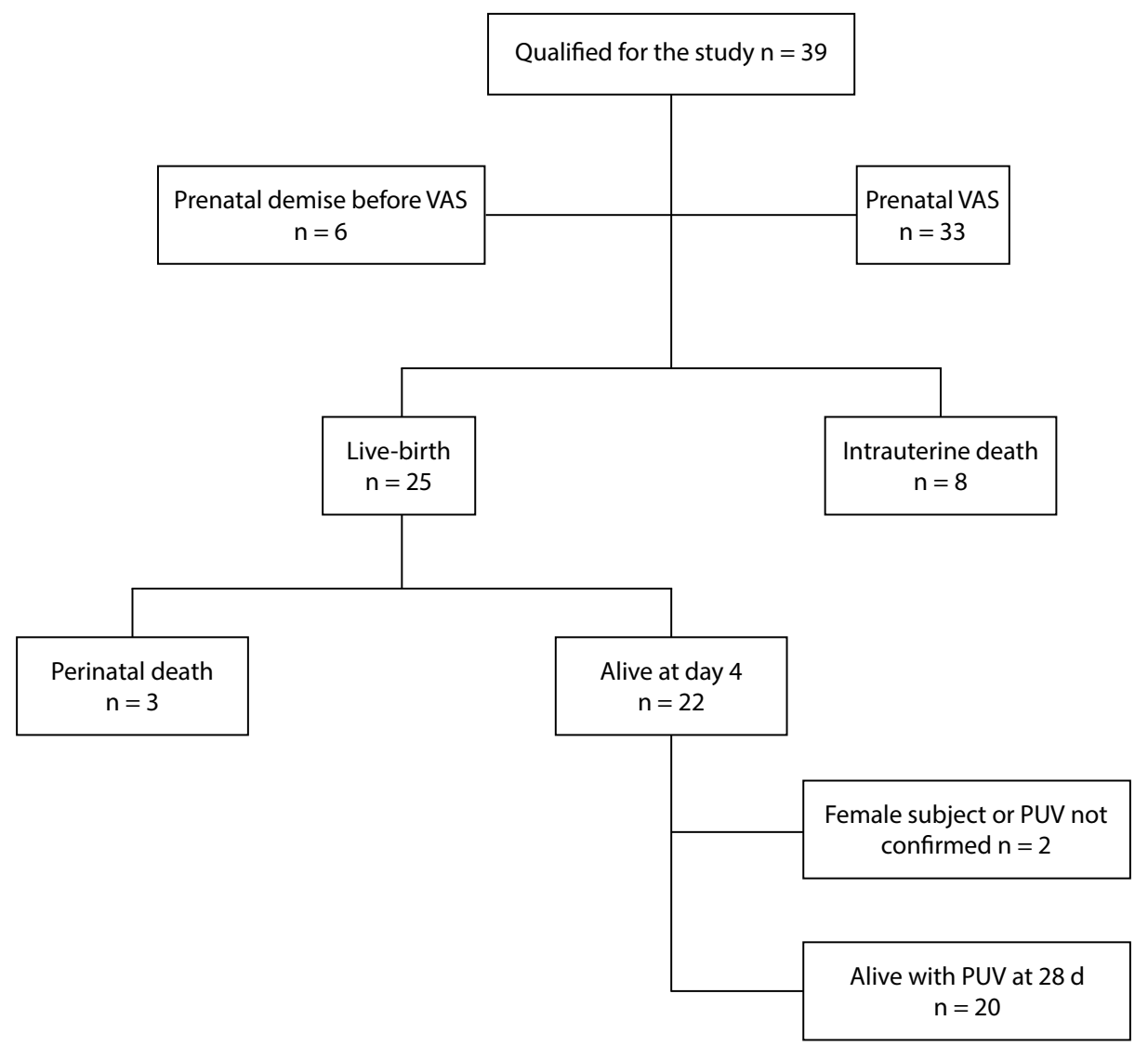

Figure 1. Outcome flowchart in the study group

to shunt insertion, amnioinfusion was performed due to technical difficulties (anhydramnios). Clinical characteristics of pregnancies are presented in Table 1.

20 patients were confirmed by postnatal evaluation to have PUV. In 10 foetuses diagnosis was confirmed by pathomorphology evaluation. There were also 1 urethral atresia (UA, in female) and in one no significant malformation of urinary tract was detected. There were 8 intrauterine deaths at mean age of $26 \mathrm{hbd}$ (range 18-29). The deaths were noted with functioning shunts in a mean time of 3 weeks after shunting. 25 children were born at the mean age of 34 weeks (range 24-39 hbd) with mean Apgar score of 8 (range 1-10).

Anthropometrical, clinical and biochemical data of the live-born children with comparison of non-survivors and survivors at 28 day are presented in Table 4. We observed that those neonates who died after birth had lower birth age, body mass, head circumference and Apgar score.

Radiological and clinical investigations confirmed LUTO in 24/25 newborns (PUV-23, UA-1). 6 children had urinary tract diversions in neonatal period and 16 cystoscopy with electroresection of the PUV within 28 days. No patient had hypertension. 21/25 required intensive care with cardiac support with vasoactive amines and ventilation support (for the mean 2.4 days — range 1-20). Mean ICU stay was
36 days (1-150 d.). Radiological features of lung hypoplasia were detected in $6 / 25$ neonates. We noted 3 deaths within first 3 days of life because of cardio-pulmonary insufficiency with lung hypoplasia. At $4^{\text {th }}$ day $18 / 22$ required mechanical ventilation but at $28^{\text {th }}$ day all children were free of mechanical support. In 2/22 clinical features of pulmonary hypoplasia were present at this time. No child amongst those who survived required oxygen supplementation at the end of neonatal period.

Renal function was compromised in $13 / 22$ of subjects who survived with mean eGFR on $4^{\text {th }}$ day of 16.2 (4-47) $\mathrm{mL} / \mathrm{min} / 1.73 \mathrm{sqm}$. Serum creatinine was elevated also in $13 / 22$ when compared to the reference from $7^{\text {th }}$ day published by Rudd. [10]. 12 out of 22 neonates had significant acidosis and 11/22 proteinuria (mean: 102 ; r: 25-339 mg/dL). ACR was significantly elevated in $86 \%$ of cases (Tab. 4).

Three out of $25(12 \%)$ children were treated with peritoneal dialysis at $4^{\text {th }}$ day (for 3 to 19 days) - and all survived, while no one required it at the $28^{\text {th }}$ day because of renal function improvement.

Overall survival rate at $28^{\text {th }}$ day was $56 \%$ among whole LUTO group of patients. In PUV patients it was lower $20 / 37-54 \%$, but in those who underwent VAS $-20 / 30-66 \%$. 
Table 4. Clinical and biochemical characteristics of neonates from the study group (median and min-max range

\begin{tabular}{|c|c|c|c|c|}
\hline & All subjects & Survivors at 28d & $\begin{array}{l}\text { Non-survivors (demise/ } \\
\text { stillbirth/death) }\end{array}$ & Statistical difference \\
\hline OU confirmed & $38 / 39$ & $21 / 22$ & $10 / 17^{*}$ & NA \\
\hline Gender (M:F) & $38 / 1$ & $21 / 1$ & $17 / 0$ & NA \\
\hline Birth age [weeks] & $33(24-39)$ & $35(29-39)$ & $30(24-32)$ & 0.001 \\
\hline Apgar score at $5 \mathrm{~min}$. & $8(1-10)$ & $9(4-10)$ & $6(1-6)$ & 0.001 \\
\hline Weight [g] & $2.4(0.5-4.4)$ & $2.6(1.5-4.4)$ & $1.8(0.5-1.9)$ & 0.005 \\
\hline Lenght $[\mathrm{cm}]$ & $47(28-57)$ & $49(41-57)$ & $41(28-42)$ & 0.002 \\
\hline Head circumferrence & $31(15-38)$ & $32(27-38)$ & $30(15-32)$ & 0.002 \\
\hline Ventilation support after birth [\%] & $21 / 25$ & $18 / 22$ & $3 / 3$ & NA \\
\hline Oxygen dependency at birth [\%] & $24 / 25$ & $21 / 22$ & $3 / 3$ & NA \\
\hline Pulmonary hypoplasia at $28 \mathrm{~d}$ [\%] & NA & $2 / 22$ & NA & NA \\
\hline ACR at $4 \mathrm{~d}[\mathrm{mg} / \mathrm{mg}]$ & NA & $\begin{array}{l}7.7 * * \\
(2.6-30)\end{array}$ & NA & NA \\
\hline Serum creatinine at $4 \mathrm{~d}[\mathrm{mg} / \mathrm{dL}]$ & NA & $1.7(0.5-1.74)$ & NA & NA \\
\hline eGFR at $4 \mathrm{~d} .[\mathrm{mL} / \mathrm{min} / 1.73 \mathrm{BSA}]$ & NA & $10(4-37)$ & NA & NA \\
\hline ACR at $28 \mathrm{~d}[\mathrm{mg} / \mathrm{mg}]$ & NA & $\begin{array}{l}4.7^{* * *} \\
(0.05-13.5)\end{array}$ & NA & NA \\
\hline Serum creatinine at $28 \mathrm{~d}[\mathrm{mg} / \mathrm{dL}]$ & NA & $0.95(0.25-4.7)$ & NA & NA \\
\hline eGFR at $28 \mathrm{~d} .[\mathrm{mL} / \mathrm{min} / 1.73 \mathrm{BSA}]$ & NA & $20.6(5-79)$ & NA & NA \\
\hline Urine output $[\mathrm{mL} / \mathrm{kg} / \mathrm{h}]$ at $4 \mathrm{~d}$ & NA & $3.4(1.0-7.5)$ & NA & NA \\
\hline Dialysis need [\%] & $3 / 25$ & $3 / 22$ & $0 / 3$ & NA \\
\hline Dialysis lenght [d] & $3-19$ & NA & NA & NA \\
\hline ICU stay [d] & NA & $19(1-150)$ & NA & NA \\
\hline Acidosis at 28day & NA & $9 / 22$ & NA & NA \\
\hline $\mathrm{HCO} 3[\mathrm{mmol} / \mathrm{l}]$ & NA & $10(17-25)$ & NA & NA \\
\hline
\end{tabular}

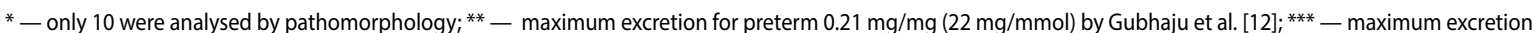
for preterm $0.11 \mathrm{mg} / \mathrm{mg} \mathrm{(15} \mathrm{mg/mmol)} \mathrm{Gubhaju} \mathrm{et} \mathrm{al.} \mathrm{[12];} \mathrm{eGFR} \mathrm{—} \mathrm{estimated} \mathrm{glomerular} \mathrm{filtration} \mathrm{rate;} \mathrm{NA} \mathrm{—} \mathrm{not} \mathrm{applicable;} \mathrm{OU} \mathrm{—} \mathrm{obstructive} \mathrm{uropathy}$

Kidney injury markers were also tested at the end of neonatal period. 12/22 (54\%) neonates had impaired eGFR (13/33 elevated creatinine) with eGFR of 24 (range 5-19) $\mathrm{mL} / \mathrm{min} / 1.73 \mathrm{~m}^{2} \mathrm{BSA}, 18$ (82\%) had increased albumin excretion (mean 5.4 range $0.05-13.5 \mathrm{mg} / \mathrm{mg}$ ). When the combined renal survival (free of any injury) of the initial group (39) was analysed, it turned out to be significantly low - 18\% (7/39). When only who survived neonatal period were qualified the percentage rose to $32 \%(7 / 22)$.

When we compared the data of foetuses (children) who survived with the other only several significant differences were detected. Normal foetal urine osmolarity was detected in $10 / 22$ foetuses who survived and in only $1 / 17$ who did not $(p=0.03)$. We also found that in the former group AFI was higher ( $8 v$ s. $4, p=0.04)$. Borderline significance was achieved with the age of the first VAS ( 21 vs. $19 \mathrm{hbd}, \mathrm{p}=0.056$ ).

We aimed at determining any prenatal marker of 28-day survival in the study group. Clinical markers of the pregnancy and VAS intervention, sodium, chloride, $\beta 2$-microglobulin urine concentration, urine osmolarity, amniotic fluid index, presence of dysplastic changes in renal parenchyma were initially included. Using common statistical tests and discriminant analysis, we only found that the survival rate was higher in those who were shunted. To validate the discriminative quality of shunting for prediction of survival we used a probabilistic predictive Naïve Bayes model. The assessed sensitivity the model was of 0.718 and precision of 0.812 with a low value of AUC equalled 0.528. The combination AFI, shunting and normal urine osmolarity assessed at the moment of diagnosis were characterised similarly: sensitivity of 0.744 , precision of 0.743 with AUC 0.850 . No other single predictor or combination of predictors were recorded as prognostic.

In the Kaplan Meyer analysis at $28^{\text {th }}$ day we observed that foetuses with at least 2 (out of 3 standard) abnormalities in the urine analysis differed with regard to outcome (Fig. 2).

\section{DISCUSSION}

We aimed our study to assess short-term outcome in LUTO. The patients remained under care of the same team 


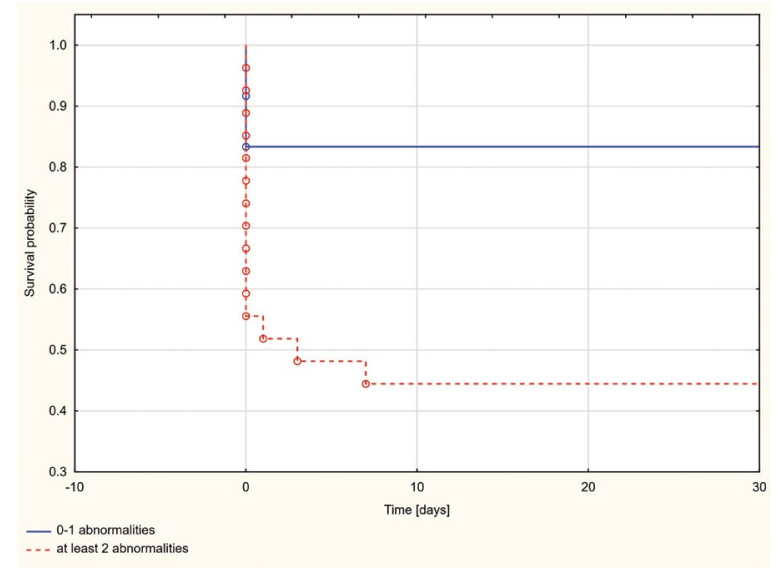

Figure 2. Kaplan-Meyer survival curves for all subjects and adjusted to the presence of negative prognostic factors in fetal urine analysis

until the end of pregnancy and at least up to $28^{\text {th }}$ day after delivery.

Prenatal diagnosis was confirmed in $87.6 \%$ cases. We found that overall survival rate in LUTO qualified for shunting at $28 \mathrm{~d}$ was $56 \%$, however when only shunted foetuses were included it rose to $66 \%$. When the renal function preservation was analysed, we showed that significant number of children had compromised eGFR at $4^{\text {th }}$ day from delivery with need for temporary dialysis in $3 / 22$. Proteinuria in this group of patients was also a frequent marker of kidney injury. Only $18 \%$ of initially qualified subject survived until neonatal period with no kidney injury (eGFR decrease or significant proteinuria). VAS preserved renal function in $7 / 22$ children who survived (32\%). The overall $28 \mathrm{~d}$ survival rate was similar to those reported in other single and multicentre trials.

The analysis conducted by Morris et al. done on basis of PLUTO randomised controlled trial and prospective observational cohort study reported 28 day survival rate as $50 \%$ and $40 \%$ respectively [6]. What was surprising, this survival rate was significantly lower than in the conservatively managed patients. Survival to 28 days after delivery was higher in the conservative-management group, at $69 \%$ (24/35), compared to $40 \%(4 / 10)$ in the VAS group $(p=0.02)$. Compared to the conservative-management group of the trial, a higher proportion of women in this registry opting for conservative management had a normal amniotic fluid volume at diagnosis $(p=0.05)$ and a diagnosis of LUTO $\geq 24$ weeks' gestation $(p=0.003)$. On multivariable logistic regression analysis, these variables showed a significant association with perinatal survival $(p<0.001)[6]$.

Ruano group assessed the 2-y outcome after foetal intervention in 50 patients with LUTO. They found PUV in 31 (62\%) foetuses, urethral atresia (UA) in 14 (28\%) foetuses, and urethral stenosis (US) in 5 (10\%) foetuses. There were no survivors in the UA group. Eleven (22.9\%) infants died during the neonatal period because of prematurity, lung hypoplasia or renal failure [13]. Short term survival rate in all abnormalities was $36 \%$ (18/50) which is comparable to our data.

Ethun et al. [14] analysed outcome of 14 patients after prenatal intervention of LUTO and showed similar results to our observation with regard to success and complications. Jeong et al. [15] showed among the 32 foetuses examined that: 5 died because of termination of pregnancy, and 2 died in utero. Three neonatal deaths occurred, resulting in an overall perinatal survival rate of $68.8 \%$ (22 of 32 ). Fontanella et al. [16] analysed the data of foetuses at high-risk of isolated LUTO and managed conservatively. The survival rate was $42 \%$ and was similar to our observation. Martinez et al. performed 20 fetal PUV ablations at the median gestational age of 18.1 weeks (range 15.0-25.6). Overall, there were 9 (45\%) terminations of pregnancy and 11 women (55\%) delivered a liveborn baby at a mean gestational age of 37.3 (29.140.2) weeks. No infants who survived developed pulmonary hypoplasia and all were alive at 15-110 months [17]. Johnson et al. [18] in the cohort study on LUTO in USA reported even higher percentage of perinatal survival (97\%), but surprisingly dialysis was required in $32 \%$ of patients.

Ruano et al. analysed retrospectively a cohort of 111 foetuses with LUTO. They showed that the probability of survival was significantly higher with foetal cystoscopy and VAS when compared to no intervention [adjusted relative risk (ARR) $1.86(95 \% \mathrm{Cl}, 1.01-3.42 ; \mathrm{p}=0.048)$ and ARR, $1.73(95 \% \mathrm{Cl}$, $1.01-3.08 ; p=0.04$ ) respectively]. Unfortunately, there was no statistically significant chance for maintaining normal kidney function in short and long-term observation. However, when they analysed only PUV patients, the situation turned out to be more optimistic. Foetal cystoscopy was effective in improving both the 6-month survival rate and renal function [ARR $4.10(95 \% \mathrm{Cl}, 1.75-9.62 ; \mathrm{p}<0.01)$ ] and $2.66[(95 \% \mathrm{Cl}, 1.25-5.70 ; \mathrm{p}=0.01)$ respectively] while VAS was associated only with an improvement in the 6-month survival rate [ARR $3.76(95 \% \mathrm{Cl}, 1.42-9.97 ; \mathrm{p}<0.01)$ ] with no effect on renal function (ARR 1.03 [95\% Cl, 0.49-2.17, $p=0.93]$ ) [5].

We found that shunting with VAS was successful in prevention of renal injury in the neonatal period only in $18 \%$ of patients from the initially qualified group. From those who survived $32 \%$ were free of any injury. In the study of Martinez et al. [17] on 20 PUV ablations, 8 ( $40 \%$ of all foetuses, $72.7 \%$ of newborns) had normal renal function and $3(27.3 \%)$ had CKD awaiting renal transplantation. They assessed the kidney injury by eGFR decrease with no data on proteinuria. Similarly, Ruano et al. [13] reported that among the infants with PUV $17 / 30$ (56.7\%) survived and 13/17 (76.5\%) had normal renal function at 1 year of life; $15 / 28$ (53.6\%) survived and $11 / 15$ (73.3\%) had normal renal function at 2 years.

Our study showed that classical prognostic factors did not differ between the survivors and non survivors group. 
Only a combination of predictors (shunting, urine osmolarity and AFI) showed little value in this prediction. In the Kaplan-Meier curve analysis foetuses with at least 2 increased classical biochemical parameters (osmolarity, sodium and chloride concentration) had lower survival rate. These results are concordant with other studies, where only combined prenatal factors were potentially qualified as significant in multivariate analysis [5, 14, 18, 19].

We are aware of the weaknesses of the study. The number of patients included was relatively small, but that was a single centre analysis. Only multicentre studies presented significantly higher number of patients. Furthermore, there was no comparator (conservative treatment) arm in the study group, nor the randomisation was possible. However, this weakness may turn into some strength. Because of specific treatment policy of the centre and profile of the country our cohort was complete and all of the pregnant women with LUTO diagnosis referred in second trimester were proposed an intervention with no option of termination of pregnancy based on patient decision. The number of patients at the first sight would look low, but when it is compared to single arms of PLUTO studies and other papers it could be qualified as one of the largest prospective cohort of VAS ever published [6]. One can postulate that the location of neonatal and urology-nephrology centre in once place increases the value of observation and quality of data. The data gathered in the neonatal period concerning comorbidities and development should enrich the value of observation. The broad range of VAS intervention (up to 30 week) also decreases the precision and value of observation but similar approach was also presented by other authors.

\section{CONCLUSIONS}

Our study led to clinically important conclusions that pregnancies with LUTO fulfilling criteria for prenatal interventions had significant percentage of unfavourable outcome. The full prevention of the kidney injury in live-born subject was difficult to achieve. However, the need of early neonatal dialysis was relatively low.

\section{Acknowlegdements}

The study was granted by Polish Mothers Memorial Hospital Research Institute - internal grant 2016/IV/54-GW.

\section{Conflict of Interests}

The authors declare that they have no conflict of interests.

\section{REFERENCES}

1. Farrugia MK. Fetal bladder outlet obstruction: Embryopathology, in utero intervention and outcome. J Pediatr Urol. 2016; 12(5): 296-303, doi: 10.1016/j.jpurol.2016.05.047, indexed in Pubmed: 27570093.
2. Clayton $D$, Brock J. Current State of Fetal Intervention for Lower Urinary Tract Obstruction. Curr Urol Rep. 2018; 19(1), doi: 10.1007/s11934018-0760-9.

3. Smith-Harrison LI, Hougen HY, Timberlake MD, et al. Current applications of in utero intervention for lower urinary tract obstruction. J Pediatr Urol. 2015; 11(6): 341-347, doi: 10.1016/j.jpurol.2015.07.012, indexed in Pubmed: 26441047.

4. Nef S, Neuhaus TJ, Spartà G, et al. Outcome after prenatal diagnosis of congenital anomalies of the kidney and urinary tract. Eur J Pediatr. 2016; 175(5): 667-676, doi: 10.1007/s00431-015-2687-1, indexed in Pubmed: 26805407.

5. Ruano R, Sananes N, Sangi-Haghpeykar H, et al. Fetal intervention for severe lower urinary tract obstruction: a multicenter case-control study comparing fetal cystoscopy with vesicoamniotic shunting. Ultrasound Obstet Gynecol. 2015; 45(4): 452-458, doi: 10.1002/uog.14652, indexed in Pubmed: 25157756.

6. Morris RK, Middleton LJ, Malin GL, et al. PLUTO Collaborative Group. Outcome in fetal lower urinary tract obstruction: a prospective registry study. Ultrasound Obstet Gynecol. 2015; 46(4): 424-431, doi: 10.1002/uog.14808, indexed in Pubmed: 25689128.

7. Pope JC, Brock JW, Adams MC, et al. How they begin and how they end: classic and new theories for the development and deterioration of congenital anomalies of the kidney and urinary tract, CAKUT. J Am Soc Nephrol. 1999; 10(9): 2018-2028, indexed in Pubmed: 10477156.

8. Morris RK, Malin GL, Quinlan-Jones E, et al. Percutaneous vesicoamniotic shunting in Lower Urinary Tract Obstruction (PLUTO) Collaborative Group. Percutaneous vesicoamniotic shunting versus conservative management for fetal lower urinary tract obstruction (PLUTO): a randomised trial. Lancet. 2013;382(9903): 1496-1506, doi: 10.1016/S01406736(13)60992-7, indexed in Pubmed: 23953766.

9. Nassr AA, Shazly SAM, Abdelmagied AM, et al. Effectiveness of vesicoamniotic shunt in fetuses with congenital lower urinary tract obstruction: an updated systematic review and meta-analysis. Ultrasound Obstet Gynecol. 2017; 49(6): 696-703, doi: 10.1002/uog.15988, indexed in Pubmed: 27270578.

10. Rudd PT, Hughes EA, Placzek MM, et al. Reference ranges for plasma creatinine during the first month of life. Arch Dis Child. 1983; 58(3): 212-215, doi: 10.1136/adc.58.3.212, indexed in Pubmed: 6838252.

11. Schwartz GJ, Feld LG, Langford DJ. A simple estimate of glomerular filtration rate in full-term infants during the first year of life.J Pediatr. 1984; 104(6): 849854, doi: 10.1016/s0022-3476(84)80479-5, indexed in Pubmed: 6726515.

12. Gubhaju L, Sutherland MR, Horne RSC, et al. Assessment of renal functional maturation and injury in preterm neonates during the first month of life. Am J Physiol Renal Physiol. 2014; 307(2): F149-F158, doi: 10.1152/ajprenal.00439.2013, indexed in Pubmed: 24899060.

13. Sananes N, Cruz-Martinez R, Favre R, et al. Two-year outcomes after diagnostic and therapeutic fetal cystoscopy for lower urinary tract obstruction. Prenat Diagn. 2016; 36(4): 297-303, doi: 10.1002/pd.4771, indexed in Pubmed: 26739350.

14. Ethun CG, Zamora IJ, Roth DR, et al. Outcomes of fetuses with lower urinary tract obstruction treated with vesicoamniotic shunt: a single-institution experience. J Pediatr Surg. 2013; 48(5): 956-962, doi: 10.1016/j. jpedsurg.2013.02.011, indexed in Pubmed: 23701767.

15. Jeong BD, Won HS, Lee MY. Perinatal Outcomes of Fetal Lower Urinary Tract Obstruction After Vesicoamniotic Shunting Using a Double-Basket Catheter. J Ultrasound Med. 2018; 37(9): 2147-2156, doi: 10.1002/jum.14565, indexed in Pubmed: 29498072.

16. Fontanella $F$, van Scheltema PN, Duin L, et al. Antenatal staging of congenital lower urinary tract obstruction. Ultrasound Obstet Gynecol. 2019; 53(4): 520-524, doi: 10.1002/uog.19172, indexed in Pubmed: 29978555.

17. Martínez JM, Masoller N, Devlieger R, et al. Laser ablation of posterior urethral valves by fetal cystoscopy. Fetal Diagn Ther. 2015; 37(4): 267-273, doi: 10.1159/000367805, indexed in Pubmed: 25614247.

18. Johnson MP, Danzer E, Koh J, et al. North American Fetal Therapy Network (NAFTNet). Natural History of Fetal Lower Urinary Tract Obstruction with Normal Amniotic Fluid Volume at Initial Diagnosis. Fetal Diagn Ther. 2018; 44(1): 10-17, doi: 10.1159/000478011, indexed in Pubmed: 28700992.

19. Matsell DG, Yu S, Morrison SJ. Antenatal Determinants of Long-Term Kidney Outcome in Boys with Posterior Urethral Valves. Fetal Diagn Ther. 2016; 39(3): 214-221, doi: 10.1159/000439302, indexed in Pubmed: 26375276 . 